\title{
Gametic Embryogenic Response in Wild Diploid Solanum Species and its Implications for Genome Sequencing Projects and Breeding
}

\author{
A. Castillo* , P. Gaiero' ${ }^{1}$ B. López Carro ${ }^{2}$ and F. Vilaró \\ Biotechnology Unit, National Institute of Agricultural Research, route $48 \mathrm{~km}$ 10. PC \\ 90200, Canelones, Uruguay
}

Key words: Haploid, Double haploid, Anther culture, Flow cytometry

\begin{abstract}
The anther culture response in Solanum commersonii $(2 \mathrm{n}=2 \mathrm{x}=24,1 \mathrm{EBN})$ and $S$. chacoense ( $2 \mathrm{n}=2 \mathrm{x}=24,2 \mathrm{EBN})$, two wild potato germplasm resources was studied to obtain haploid plants. Three accessions from each of the two species and 3200 anthers from each genotype were cultured. Authors assessed different culture media; ascorbic acid, L-cysteine and silver nitrate $\left(\mathrm{AgNO}_{3}\right)$ were included to prevent browning of anther cultures. Addition of $\mathrm{AgNO}_{3}$, was effective to induce embryogenesis. The clones from $S$. commersonii showed different embryogenic response to androgenesis. However, the three accessions from S. chacoense did not induce any embryo in the same conditions. Ploidy level of the regenerated clones was estimated by flow cytometry and confirmed by chromosome counts. This is the first report of haploid plants obtained from anther culture in $S$. commersonii, with important implications in sequencing efforts and potato breeding.
\end{abstract}

\section{Introduction}

Cultivated potato (Solanum tuberosum $\mathrm{L}$. $(2 \mathrm{n}=4 \mathrm{x}=48,4 \mathrm{EBN})$ is a vegetatively propagated crop with tetrasomic inheritance and a high level of heterozygosity (Tai and Xiong 2005). Potato breeding and genetics are also difficult because the species shows strong inbreeding depression which causes a reduction in viability

*Corresponding author: <acastillo@inia.org.uy>. ${ }^{*}$ Department of Plant Biology, Faculty of Agronomy, University of the Republic. Avda. Garzón 780. PC 12900, Montevideo, Uruguay. <pgaiero@fagro.edu.uy>. ${ }^{2}$ Flow Cytometry and Cell Sorting Core, Institute of Biological Research Clemente Estable. (IIBCE). Av. Italia 3318. PC 11600, Montevideo, Uruguay. <bealc57@gmail.com>. 
when selfed (De Jong and Rowe 1991, Bradshaw 2007). It also has selfincompatibility at the diploid level (Bradshaw 2007). Despite the novel developments in genetic mapping using an inbred line-derived $F_{2}$ population (Endelman and Jansky 2016), dihaploids and monoploids are still the tools of choice for genetic, cytogenetic and evolutionary studies (Rokka 2009). In the context of the Potato Genome Sequencing Consortium (PGSC 2011), the doubled monoploid clone (DM1-3 516R44) developed by Veilleux et al. (1995) allowed a reference assembly, because the DM1-3 clone is a completely homozygous line, which eliminates the complexity brought into the assembly by heterozygosity (Visser et al. 2009). The production of haploids and dihaploids provide an attractive biotechnological technique for breeding purposes (reviewed by Peloquin et al. 1991) i.e. in a single step a complete homozygous line can be developed from heterozygous parents, avoiding time-consuming rounds of selfing (Germanà 2011). Potato monoploids can be used in crosses with wild species (reviewed by Jansky 2006) and also in protoplast fusion to produce somatic hybrids (Lightbourn and Veilleux 2007).

Potato breeders have used wild species related to $S$. tuberosum as a source of resistance against pathogens and abiotic stresses (Jansky et al. 2006) and to broaden the genetic base of the crop, which is limited because of the few genotypes that were first introduced in Europe and then used in breeding (Birch et al. 2012). The use of resistant varieties incorporating valuable traits from wild diploid species is an interesting approach to achieve higher quality and yield in potatoes and other crops (Zuluaga et al. 2015).

Solanum commersonii $(2 \mathrm{n}=2 \mathrm{x}=24,1 \mathrm{EBN})$ and $S$. chacoense are wild tuberbearing species native to Southern South America. They present wide genetic variability and resistance to different biotic stresses (in the case of S. commersonii, resistance to the second most important potato disease, bacterial wilt caused by Ralstonia solanacearum), tolerance to cold and drought conditions, high genetic diversity and adaptability (Pianzzola et al. 2005). The main bottleneck for their use in potato breeding is the need for ploidy manipulation to overcome hybridization barriers.

Ploidy manipulation to produce haploids or monoploids in potato can be performed through either pollination with haploid inducers or anther culture (androgenesis). Pollination with haploid inducers is more common in $S$. tuberosum using clones of diploid Group Phureja (Hougas et al. 1958, Peloquin et al. 1996, Panahandeh 2010). This method has its drawbacks because there is evidence that some chromosomal segments from the Group Phureja pollinator remain in some aneusomatic genotypes and that there was incorporation of DNA from the pollinator via somatic translocation, suggesting that the mechanism is 
chromosome elimination instead of parthenogenesis (Wilkinson et al. 1995, Ercolano et al. 2004). The production of haploids through anther culture has many advantages since it does not imply the inbreeding depression caused by selfing and does not involve pollinator genome contamination.

Many factors are involved and interact in the optimization of the anther culture protocol to produce haploid plants; therefore it is necessary to consider: pre-treatment of anthers, genotype effects, the stage of pollen development, culture conditions and induction of embryos and regeneration of plants. These factors greatly affect the response of the microspores to achieve reprogramming cells to the sporophytic route (Germanà 2011).

Both cultivated and wild potato genotypes differ in their potential for embryogenesis and regeneration in anther culture (Sonnino et al. 1989, Aziz et al. 1999, Paz and Veilleux 1999). Genotype is the main endogenous factor affecting regeneration (Germanà 2011). Therefore, if haploid plants are to be regenerated via androgenesis, potato germplasm must be screened for anther culture response.

Among the different pretreatments described in the literature, cold has been reported as a stress factor that induces the switch from the gametophytic to the sporophytic pathway in the male gametophyte (reviewed by Shariatpanahi et al. 2006).

Culture medium composition is a very important aspect to evaluate embryogenesis response (Canhoto et al. 1990). Among other medium components, $\mathrm{AgNO}_{3}$ acts as an ethylene inhibitor, delaying anther senescence (Lentini et al. 1995) and blocking its negative effects on embryogenesis (Kumar et al. 2009) and embryo development (Sarropoulou et al. 2016). This compound effectively prevents in vitro-cultured explants from ethylene harm avoiding growth inhibition in Solanum tissue culture (Tiainen 1992) and delays browning by competing with ethylene for the binding site located predominantly at the intracellular membrane (Veen and Overbeek 1988), thus allowing the formation of more haploid plants in anther culture. Exogenous plant growth regulators are one of the most important keys to successful induction of haploid plants through microspore embryogenesis using anther culture (Germanà 2011). Medium composition has been assessed for cultivated potatoes of Group Phureja (Paz and Veilleux 1999) but not for wild tuber-bearing species. There have been successful attempts and plants have been regenerated in S. chacoense and interspecific hybrids (Cappadocia et al. 1984) but no studies have been reported for $S$. commersonii.

After plant regeneration in anther culture, ploidy level must be checked because plants may regenerate from mother plant tissues like the anther wall, 
through nuclei fusion or endomitosis (Germanà 2011 and references therein). Several approaches are available to confirm ploidy level, being genome size quantification through flow cytometry and chromosome counting the most suitable (Doležel 1991, Doležel and Bartôs 2005).

The aim of this study was to screen the selected diploid genotypes of Solanum commersonii and S. chacoense clones for their regeneration response in anther culture and to evaluate protocols to obtain haploid plants from anther culture in these species.

\section{Materials and Methods}

Plant material was selected from the in vitro germplasm collection of diploid genotypes of Solanum commersonii and S. chacoense established in the tissue culture laboratory in INIA "Las Brujas" from field collections of natural populations in Uruguay. Different genotypes from S. commersonii and S. chacoense were included in the 3 assays. Shoots were cultured in vitro in MS with 3\% (w/v) sucrose and modified Staba vitamins (1969) in the growth chamber 16/8 hrs day/night cycle with light intensity of $15 \mu \mathrm{mol} / \mathrm{m} / \mathrm{s}$ for 4 weeks at $21 \pm 2^{\circ} \mathrm{C}$. Fifteen rooted plantlets from each clone were acclimated in the greenhouse. All plants were transplanted to a commercial peat-based growth medium (Tref PP4) and maintained in a greenhouse to promote active growth and blooming. The conditions in the greenhouse were $16 \mathrm{hrs}$ photoperiod, $15^{\circ} \mathrm{C}$ (night) and $20 \pm 5^{\circ} \mathrm{C}$ (day).

Experiment 1: Anther culture response in different liquid media: Clone $\mathrm{cmm} 3$ was used in this experiment. Blooming started after two months under the above mentioned conditions in the greenhouse (Fig. 1a). Flower buds that were at the uninucleate pollen stage estimated by their length of $4-6 \mathrm{~mm}$ (Fig. 1b) after checking one anther per flower bud size with the acetocarmine method (Fig. 1e) they were harvested, surface-sterilized in $100 \mathrm{ml}$ of $10 \%$ hypochlorite solution with 2 drops of Tween 20 for 15 minutes followed by three rinses in distilled sterile water and then cultured.

Flowers were opened in a laminar flow chamber; 1200 anthers were isolated with a scalpel in aseptic conditions (Fig. 1c,d) and placed in $100 \mathrm{ml}$ glass jars (Fig. 1e) containing $20 \mathrm{~mL}$ of culture liquid medium with MS mineral salts, Staba vitamins, $0,5 \mathrm{mM}$ cysteine and 1, $13 \mathrm{mM}$ ascorbic acid. Two concentrations of benzil adenine (BA): $2.27 \mu \mathrm{M}, 4.54 \mu \mathrm{M}$ were tested. Half of the treatments also contained $11.8 \mu \mathrm{M} \mathrm{AgNO}_{3}$ (Table 1, grey cells). Each jar contained 50 anthers. The $\mathrm{pH}$ medium was adjusted to 5.8 and then the medium was sterilized by autoclaving at $121^{\circ} \mathrm{C}$ and $1.1 \mathrm{~kg} / \mathrm{cm}^{2}$ for $20 \mathrm{~min}$. 

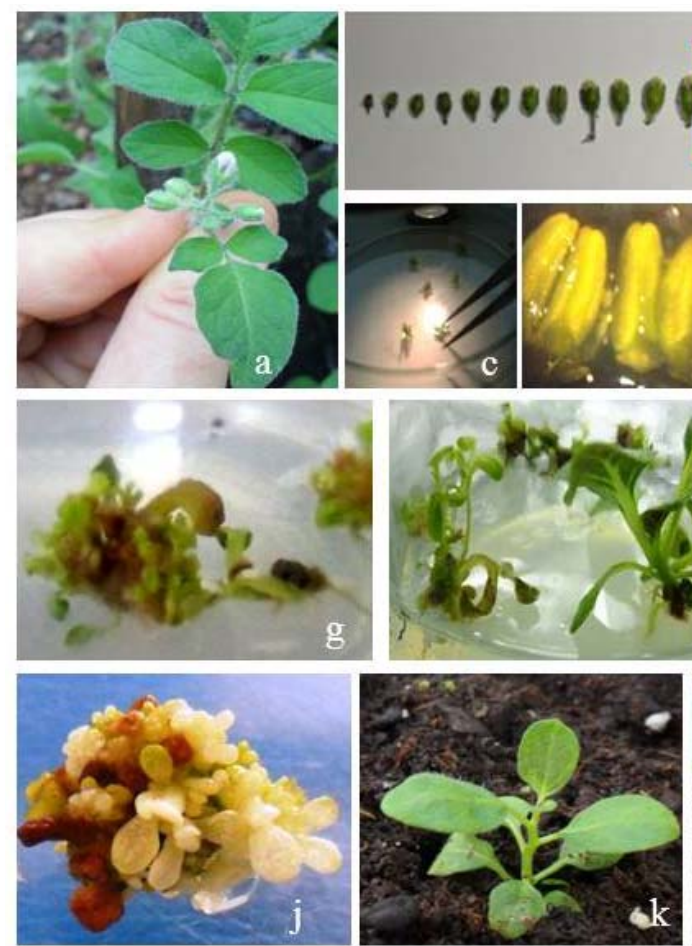
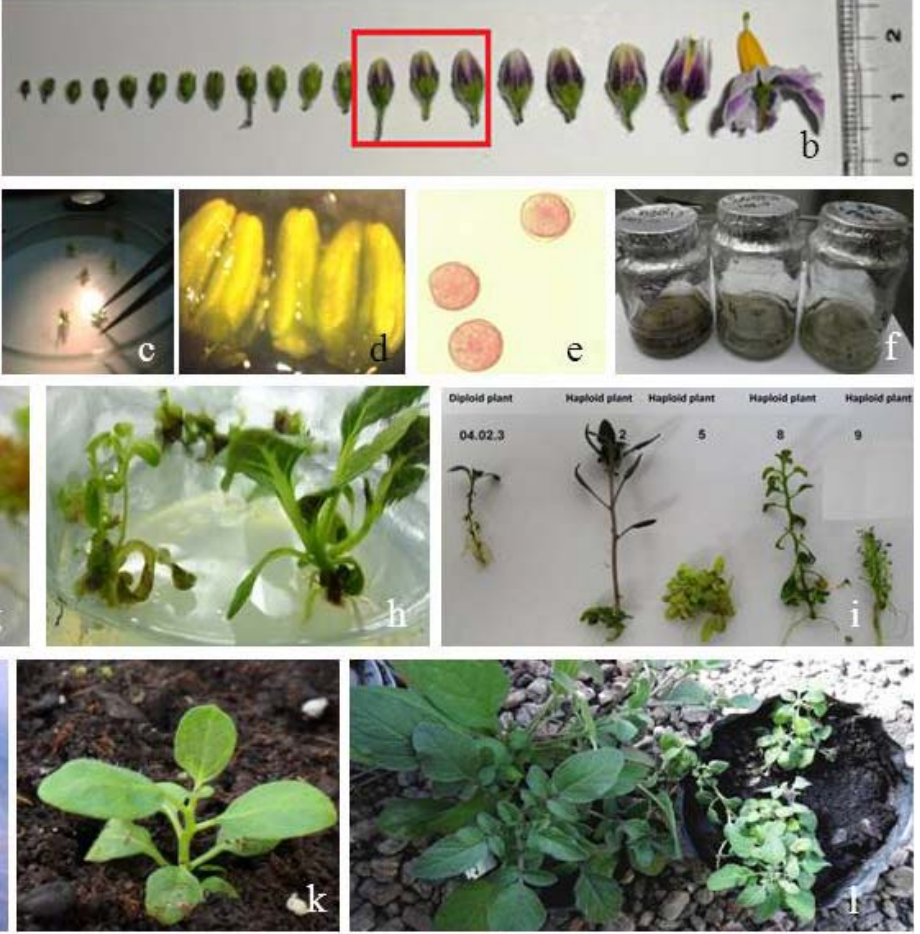

Fig. 1. Sequence of plant regeneration from anther culture in S. commersonii. a. Immature inflorescence from one of the donor clones. b. Flower bud sizes selected for anther culture. c. Isolation of anthers from selected flower buds. d. Anthers from selected flower buds. e. Pollen grains in the uninucleate state from selected anthers. f. Anthers placed in the liquid induction medium. g. Plant organogenesis from callus. h. Individual plants growing in jars. i. Morphological differences observed among different haploid plants (right) obtained from the same diploid donor (left) j. Albino plants derived from old callus. k. Acclimation of plants. 1. Acclimated plants, left: diploid donor plant, right: haploid plant.

Experiment 2: Cold pretreatment: In this case, half of the anthers were placed at $4^{\circ} \mathrm{C}$ for $48 \mathrm{hrs}$ and the other half did not go through this cold pretreatment. We included $\mathrm{cmm} 1$ and $\mathrm{cmm} 2$ clones from $S$. commersonii in addition to $\mathrm{cmm} 3$ and we added three clones from $S$. chacoense and we tested the same media as in Experiment 1 (Table 1, grey cells). Jars with anthers were placed in a shaker at $110 \mathrm{rpm}$ at $28^{\circ} \mathrm{C}$ in the dark. Fifty anthers were placed per jar with 3 replicates per treatment. The induction of anther-derived embryos was determined after 4 weeks by counting calli and the number of embryos.

Experiment 3: Media optimization for S. chacoense: Flowers of the donor plants of $S$. chacoense were selected as described for S. commersonii in Experiment 1 . In this experiment we evaluated the same medium assayed in Experiment 2 and 
also included three new treatments with $5.75 \mu \mathrm{M}$ AIA in the culture medium (Cappadocia et al. 1984) (Table 1, grey and clear cells).

Table 1. All media included MS salts $+0.17 \mathrm{M}$ sacarose $+1.13 \mathrm{mM}$ ascorbic acid and 0.5 $\mathrm{mM}$ cysteine. Grey-filled cells indicate treatments that were employed in experiments 1, 2 and 3 while clear cells indicate treatments only tested in experiment 3 .

\begin{tabular}{lccc}
\hline Medium & $\begin{array}{c}\mathrm{AgNO}_{3} \\
(\mu \mathrm{M})\end{array}$ & $\begin{array}{c}\mathrm{BA} \\
(\mu \mathrm{M})\end{array}$ & $\begin{array}{c}\text { AIA } \\
(\mu \mathrm{M})\end{array}$ \\
\hline T1 & - & - & - \\
T2 & - & 2.27 & - \\
T3 & - & 4.54 & - \\
T4 & - & - \\
T5 & 11.76 & 2.27 & - \\
T6 & 11.76 & 4.54 & - \\
T7 & 11.76 & - & 5.75 \\
T8 & 11.76 & 2.27 & 5.75 \\
T9 & 11.76 & 4.54 & 5.75 \\
\hline
\end{tabular}

Plant regeneration: After 30 days in culture, small calli and embryos grown in liquid medium were transferred to $300 \mathrm{ml}$ jars with solid medium containing 40 $\mathrm{ml}$ MS solidified with $8 \mathrm{~g} / \mathrm{l}$ plant cell culture tested agar (Sigma, St. Louis, MO). The culture medium contained MS salts, modified Staba vitamins and no growth regulators. Jars with plants were placed in the growth chamber, exposed to light $\left(16 / 8 \mathrm{hrs}\right.$ day/night cycle with light intensity of $\left.15 \mu \mathrm{mol} / \mathrm{m}^{2} / \mathrm{s}\right)$ at $21 \pm 2^{\circ} \mathrm{C}$. The final number of plants was recorded after 4 weeks on the regeneration medium.

Ploidy estimation using flow cytometry: A sample of plants obtained from anther culture was used to determine ploidy level. Nuclear suspensions for flow cytometry were prepared according to Doležel et al. (2007). Briefly, young leaves from each plant were chopped with a sharp razor blade in a glass Petri dish containing $0.5 \mathrm{ml}$ ice-cold Otto I buffer ( $0.1 \mathrm{M}$ citric acid $+0.5 \%$ Tween 20$)$, then filtered through a $50 \mu \mathrm{m}$ nylon mesh and incubated for at least $1 \mathrm{hr}$. Subsequently, $0.5 \mathrm{ml}$ of Otto II buffer $\left(0.4 \mathrm{M} \mathrm{Na}_{2} \mathrm{HPO}_{4} \cdot 12 \mathrm{H}_{2} \mathrm{O}\right.$; Otto 1990) were added. Finally, the nuclear suspensions were treated with RNAase $(50 \mu \mathrm{g} / \mathrm{ml})$ and stained with PI $(50 \mu \mathrm{g} / \mathrm{ml})$ for $10 \mathrm{~min}$. Flow cytometry measurements were performed in a FACS Vantage flow cytometer (Becton Dickinson, San José, CA) with a $70 \mu \mathrm{m}$ nozzle and an Innova 300 laser (Coherent, CA) tuned to emit at 488 $\mathrm{nm}(100 \mathrm{~mW})$. Three ploidy estimations were done for each genotype (5000 nuclei per analysis) to avoid errors due to instrumental drift or sample 
preparation. One of the diploid S. commersonii donor genotypes ( $\mathrm{cmm} 3)$ was used as external reference control.

Chromosome counting: In order to confirm ploidy level estimations, chromosome counts were performed on the clones that were classified as haploids through flow cytometry. Fast growing root tips were collected from plants grown in vitro in the above mentioned conditions (see Plant regeneration). Root tips were pre-treated in $0.002 \mathrm{M}$ 8-hydroxyquinoline for $20 \mathrm{hrs}$ at $4^{\circ} \mathrm{C}$, fixed in Carnoy solution $\left(3: 1,100 \%\right.$ ethanol : glacial acetic acid) and stored at $-20^{\circ} \mathrm{C}$. Chromosome preparations were obtained following the protocol by Zhong et al. (1996), with minor modifications. Slides were stained with 4,6-diamidino-2phenylindole (DAPI, $2 \mu \mathrm{g} / \mathrm{ml}$ ) in Vectashield (Vector Laboratories, California, USA) and were examined under a Zeiss Axioplan2 Imaging Photomicroscope equipped with epifluorescence illumination, with filter sets for DAPI. Selected images were captured using a Photometrics Sensys 1,305 $\times 1,024$ pixel CCD camera and processed using Photoshop CS4 (Adobe).

\section{Results and Discussion}

Optimization of culture medium: In terms of the media used, $\mathrm{cmm} 2$ regenerated plants in three of the treatments: T3, T5 and T6 (Table 2). Over two hundred plants derived from $\mathrm{cmm} 2$ were regenerated in medium $\mathrm{T} 3$, which contained $4.54 \mu \mathrm{M}$ BA without $\mathrm{AgNO}_{3}$ (Table 1). 55 was the best medium in terms of number of plants regenerated, with more than 400 for this clone. This medium did not include $\mathrm{BA}$, but 11, $76 \mu \mathrm{M} \mathrm{AgNO}_{3}$ was added (Table 1). In $\mathrm{T}_{6} \mathrm{AgNO}_{3}$ and BA were combined (Table 1), but the regeneration was low, with 80 plants from $\mathrm{cmm} 2$ (Table 2). We observed that $\mathrm{cmm} 2$ regenerated some albino plants associated with old calli (Fig. 1j), which can be related to the response described as "albino versus green plantlet formation" by Foroughi-Wehr et al. (1982). Our results confirmed that different species and genotypes require different concentrations and combinations for optimal growth, as reviewed by Germanà (2011). Genotype $\mathrm{cmm} 3$ seemed to be dependent on the presence of BA in the medium to regenerate plants. This genotype showed regeneration in medium T2 (only 5 plants) and $\mathrm{T} 6$ (15 plants). When $\mathrm{AgNO}_{3}$ was included, the regeneration rate increased for both clones, even in the medium without growth regulators, possibly because of its effects as ethylene inhibitor. Our results showed that the presence of this component in $\mathrm{T} 5$ produced the highest number of regenerated plants (more than 400); the same medium $\mathrm{T} 1$ without $\mathrm{AgNO}_{3}$ did not induce the formation of embryos or calli. We assume that the lack of $\mathrm{AgNO}_{3}$ allowed the production of ethylene, thereby inhibiting regeneration. 
Table 2. Number of plants obtained per donor genotype and per treatment after induction and culture media regeneration. Grey-filled cells indicate treatments that were employed in experiments 1 and 2 while clear cells indicate treatments only tested in experiment 3 . Donor genotypes that did not induce any regenerants ( $\mathrm{cmm} 1$, and chc1 to 3 ) are not included in the table.

\begin{tabular}{lcc}
\hline & \multicolumn{2}{c}{ Plant regeneration } \\
\cline { 2 - 3 } Treatment & $\mathrm{cmm} 2$ & $\mathrm{cmm} 3$ \\
\hline T1 & 0 & 0 \\
T2 & 0 & 5 \\
T3 & 239 & 0 \\
T4 & 0 & 0 \\
T5 & 434 & 0 \\
T6 & 80 & 15 \\
T7 & 0 & 0 \\
T8 & 0 & 0 \\
T9 & 0 & 0 \\
\hline
\end{tabular}

In $S$. chacoense no regeneration was observed in the media used in these experiments. In the third experiment, in addition to the media previously used, the media proposed by Cappadocia (1984) were included as positive regeneration controls for $S$. chacoense, but even these media were ineffective to induce gametic embryogenesis in the three genotypes evaluated.

Pretreatments and genotype screening: Cold pretreatments did not have any effect on regeneration rates in our experiments. There was no significant increase of regeneration when anthers were pretreated at $4^{\circ} \mathrm{C}$ for $48 \mathrm{hrs}$, neither through embryogenesis nor organogenesis responses. Similar results were attained by Wang et al. (2014) working with anther culture of lovage. On the contrary, there was a higher embryogenesis frequency in anthers cultured at room temperature compared with low temperature treatments (data not shown), suggesting that the response of the anthers to cold treatment could vary with different species and genotypes in different experimental conditions, which is consistent with reports in the literature (Powell 1988, Osolnik et al. 1993).

We obtained three different responses for the three different $S$. commersonii donor genotypes and experiments. In the first experiment we obtained direct embryo regeneration in induction medium with the $\mathrm{cmm} 3$ donor clone. Embryos floating in liquid medium were cultured in solid medium for further development. However, in the second experiment including also genotype $\mathrm{cmm} 2$, plant regeneration was obtained from calli and the development pathway 
was indirect organogenesis (Fig. 1f). Genotype $\mathrm{cmm} 2$ showed a high response; more than four hundred plants were obtained from different calli (Table 2, grey cells). In the case of cmm1 no regeneration was observed in any of the two experiments in which it was included; $\mathrm{cmm} 1$ did not produce any callus in the different culture media evaluated. Moreover, despite the vigorous development displayed under in vitro conditions (Fig. 1i), haploid individuals showed greater strain to survive during the acclimation phase (Fig. 1k, 1), which can be related with one of the components of embryogenesis ability, namely the inherited trait identified as "plantlet regeneration" by Foroughi-Wehr et al. (1982). These results showed that anther culture in Solanum commersonii is highly dependent on genotype, although a higher number of genotypes should be evaluated to draw more robust conclusions. In S. chacoense we evaluated 3 genotypes and none of them showed regeneration. Cappadocia et al. (1984) found differences in response among different genotypes and genotype-dependent culture response differences are well documented (Guha-Mukherjee 1973, Wenzel et al. 1977, Chaleff and Stolarz 1981, Sonnino et al. 1989, Aziz et al. 1999, Paz and Veilleux 1999). There is also evidence that the ability to undergo embryogenesis from microspores in potato is a heritable trait, controlled by the recessive alleles of more than one gene (Sonnino et al. 1989). It is possible that a similar situation is true for these wild potatoes and that the different clones vary in their genotype for these genes.

Anther browning was equally observed in the two species assayed but there were differences in the color changes triggered by oxidation; cmm1 anthers became dark brown in liquid medium along the first week in culture. However, for genotypes $\mathrm{cmm} 2$ and $\mathrm{cmm} 3$ oxidation was mild. S. chacoense anthers were oxidized in the three clones evaluated and the induction culture medium was colored brown, thus the response to anther oxidation was similar to $\mathrm{cmm} 1$. These results point to a relation between oxidation and lack of regeneration, but the underlying causes should be further investigated.

Characterization of regenerants: We have confirmed the haploid condition of regenerants by flow cytometry and chromosome counts (Fig. 2). The histogram peaks (Fig. 2e) were consistent with the haploid condition for all the clones tested and the chromosome number observed in the selected clones was the expected $2 \mathrm{n}=\mathrm{x}=12$ in all cells and slides analyzed (Fig. 2a-c). Wide morphological variability was observed among the regenerants (Fig. 1i), which is a great advantage of this technique. It allows recovery of regenerants that are the product of recombination, independent assortment and segregation during meiosis. One of these clones has already gone into the sequencing pipeline, 
leveraging its lack of heterozygosity in order to simplify genome sequence assembly.
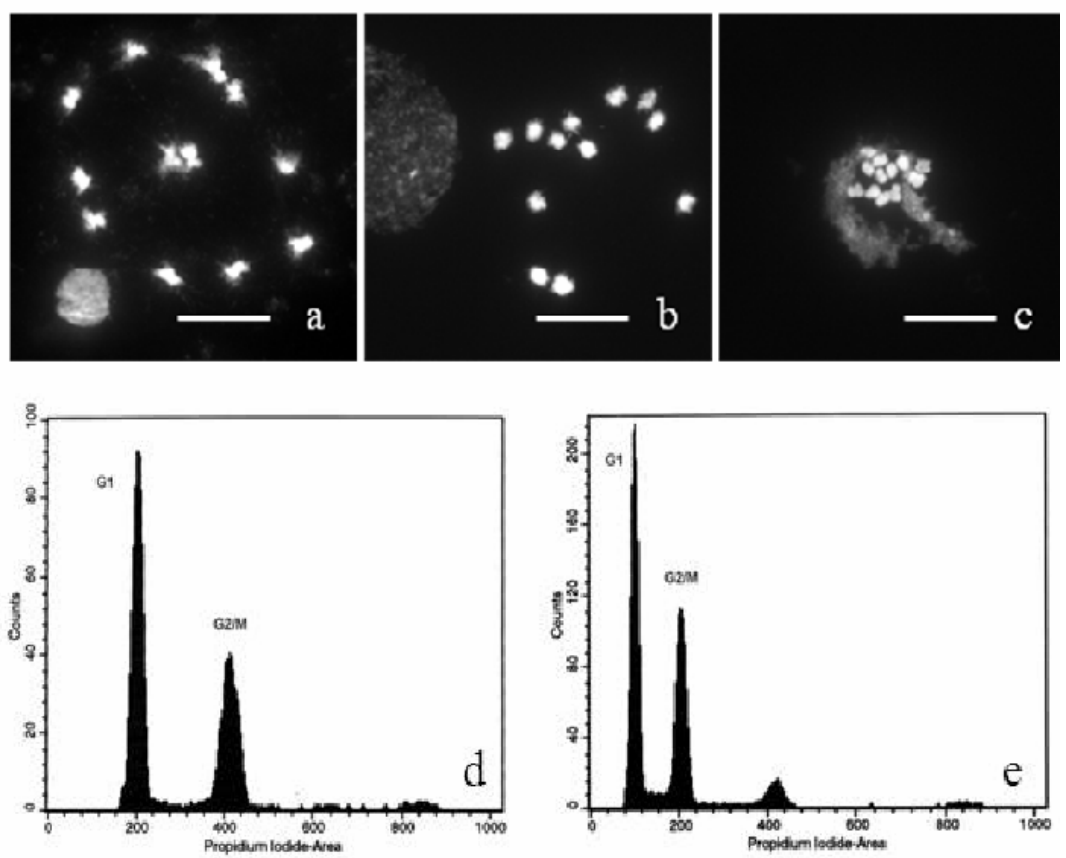

Fig. 2. Ploidy estimations of regenerants. a-c. Mitotic metaphase complements from three haploid clones derived from Solanum commersonii genotype $\mathrm{cmm} 3$ showing the haploid chromosome number $2 \mathrm{n}=\mathrm{x}=12$. a. clone 2, b. clone 3, c. clone 9. Scale bars represent $10 \mu \mathrm{m}$. d-e. Estimation of DNA content (relative fluorescence of propidium iodide-DNA stain) by flow cytometry. $\mathrm{X}$-axis represents the channel number and Y-axis gives the frequency of nuclei in each channel. $\mathrm{d}$. diploid anther donor cmm3. DNA peaks on X-axis observed ca. 220 for diploid nuclei at G1 and ca. 430 for diploid nuclei at G2. e. haploid DNA peaks on X-axis observed ca. 100 for haploid nuclei at G1 and ca. 210 for haploid nuclei at G2.

Importance of anther culture in potato research and breeding: In this study we have been able to obtain haploid clones through anther culture from different Solanum commersonii genotypes in optimized culture media and conditions. The number of plants obtained for each treatment and genotype is described in Table 2. Selected haploid genotypes have been cultivated until the potted plant stage and are comparable in vigor, flowering and tuberization to the donor diploid clone (Fig. 1k, 1). These haploid clones are of interest for both genetic and genomic studies currently underway in our research group as well as for potato breeding. Haploids plants obtained from Solanum species are useful tools for breeding and genetic research (Rokka et al. 2009). 
The anther culture technique has allowed us to obtain haploid clones without the need for repeated selfing. This would not be possible in these selfincompatible species, and if achieved by using self-compatibility genes from $S$. chacoense clones (Birhman and Hosaka 2000), it would have implied inbreeding depression (De Jong and Rowe 1971). Moreover, our haploid development did not involve a pollinator species, therefore avoiding the risk of genome contamination with genomic fragments from the pollinator remaining in the haploid clones (Wilkinson et al. 1995, Ercolano et al. 2004).

Final considerations: This is the first report of plant regeneration from anthers in S. commersonii. Our results show that it is possible to induce gametic embryogenesis in this species and that considerable diversity exists among the regenerated genotypes obtained, which may be explained via recombination, independent assortment and segregation during meiosis. In other words, it is feasible to capture genetic variability through anther culture in this species.

We recommend the use of media $\mathrm{T} 5$ (no $\mathrm{BA}$ and $11.8 \mu \mathrm{M} \mathrm{AgNO}_{3}$ ) and $\mathrm{T} 6$ $\left(4.54 \mu \mathrm{M}\right.$ BA and $\left.11.8 \mu \mathrm{M} \mathrm{AgNO}_{3}\right)$ in anther culture of $S$. commersonii. Although $\mathrm{T} 5$ produced the highest number of regenerants, medium $\mathrm{T} 6$ seems to be the most suitable for plant regeneration across genotypes, because it produced regenerants in two of the three genotypes tested. Our results confirm that regeneration capacity of microspores in S. commersonii and S. chacoense is highly dependent on the genotype. Screening of genotypes is recommended before considering a breeding program using these species or a study aimed to obtain haploids by anther culture.

\section{Acknowledgements}

This work was supported by the Agencia Nacional de Investigación e Innovación (ANII), Uruguay, under Grant Fondo María Viñas (project code FMV_1_2011_ 1_6697) and by the Comisión Sectorial de Investigación Científica, University of the Republic, under grant CSIC I+D (project code CSIC I+D 2012 383). Authors wish to thank M. Ceppa, D. Dieppa, M. Bentancor and B. Bonilla for assistance in anther culture and for laboratory work. They are also thankful to P. Esteves and P. Speranza for their useful comments on the manuscript and figures.

\section{References}

Aziz AN, Seabrook JE, Tai GC and De Jong H (1999) Screening diploid Solanum genotypes responsive to different anther culture conditions and ploidy. assessment of anther-derived roots and plantlets. Am. J. Pot. Res. 76(1): 9-16. http://link.springer. com/article/10.1007/BF02853552 
Birch PRJ, Bryan G, Fenton B, Gilroy EM, Hein I, Jones JT, Prashar A, Taylor MA, Torrance L and Toth IK (2012) Crops that feed the world 8: Potato: are the trends of increased global production sustainable? Food Secur. 4(4): 477-508. doi: 10.1007/ s12571-012-0220-1

Birhman RK and Hosaka K (2000) Production of inbred progenies of diploid potatoes using an $S$-locus inhibitor (Sli) gene, and their characterization. Genome 43(3): 495-502. http://www.nrcresearchpress.com/doi/abs/10.1139/g00-012\#.VzZuA4ThCM8

Bradshaw JE (2007) Potato-breeding strategy. In: Potato Biology and Biotechnology: Advances and Perspectives, Vreugdenhil D, Bradshaw J, Gebhardt C, Govers F, Mackerron DKL,. Taylor MA and. Ross HA (Eds.), Elsevier, The Netherlands. pp. 157-177. http://www.sciencedirect.com/science/article/pii/B9780444510181500506

Chaleff RS and Stolarz A (1981) Factors influencing the frequency of callus formation among cultured rice (Oryza sativa) anthers. Physiol. Plant. 51(2): 201-206. doi: 10. 1111/j.1399-3054.1981.tb02699.x

Canhoto J, Ludovina M, Guimarfies S and Cruz GS (1990) In vitro induction of haploid, diploid and triploid plantlets by anther culture of lochroma warscewiczii Regel. Plant Cell Tiss. Org. Cult. 21(2): 171-177. http://link.springer.com/article/10.1007/BF 00033438

Cappadocia D, Cheng S and Ludlum-Simonette R (1984) Plant regeneration from in vitro culture of anthers of Solanum chacoense Bitt. and interspecific diploid hybrids $S$. tuberosum L. × S. chacoense Bitt, Theor. Appl. Genet. 69(2): 139-143. http:// link. springer.com/article/10.1007/BF00272886

De Jong H and Rowe PR (1971) Inbreeding in cultivated diploid potatoes. Potato Res. 14(2): 74-83. http://link.springer.com/article/10.1007/BF02355931

Doležel J (1991) Flow cytometric analysis of nuclear DNA content in higher plants. Phytochem. Anal. 2(4): 143-154. doi: 10.1002/pca.2800020402

Doležel J and J Bartôs (2005) Plant DNA flow cytometry and estimation of nuclear genome size. Ann. Bot. 95(1): 99-110. doi: 10.1093/aob/mci005

Doležel J, J Greilhuber and J Suda (2007) Estimation of nuclear content in plants using flow cytometry. Nature Protocols 2(9): 2233-2244. http://www.nature.com/nprot/ journal/v2/n9/abs/nprot.2007.310.htm

Endelman JB and Jansky SH (2016) Genetic mapping with an inbred line-derived $\mathrm{F}_{2}$ population in potato. Theor. Appl. Genet. 129(5): 935-943. doi: 10.1007/s00122-0162673-7

Ercolano MR, Carputo D, Li J, Monti L, Barone A and Frusciante L (2004) Assessment of genetic variability of haploids extracted from tetraploid $(2 \mathrm{n}=4 \mathrm{x}=48)$ Solanum tuherosum. Genome 47(4): 633-638. http://www.nrcresearchpress.com/doi/abs/10.1139 /g04-020\#.VzZwjoThCM8

Foroughi-Wehr B, Friedt W and Wenzel G (1982) On the genetic improvement of androgenetic haploid formation in Hordeum vulgare L. Theor. App. Genet. 62(3): 246248. http://link.springer.com/article/10.1007/BF00276246

Germanà MA (2011) Anther culture for haploid and doubled haploid production. Plant Cell Tiss. Org. Cult. 104(3): 283-300. http://link.springer.com/article/10.1007/s11240010-9852-z\#page-1 
Guha-Mukherjee S (1973) Genotypic differences in the in vitro formation of embryoid from rice pollen. J. Exp. Bot. 24(1): 139-144. http://jxb.oxfordjournals.org/content /24/1/139.short

Hougas RWS, Peloquin J and Ross RW (1958) Haploids of the common potato. Heredity 49(3): 103-106. http://jhered.oxfordjournals.org/content/49/3/103.extract

Jansky S (2006) Overcoming hybridization barriers in potato. Plant Breed. 125(1): 1-12. http://onlinelibrary.wiley.com/doi/10.1111/j.1439-0523.2006.01178.x/abstract

Kumar V, Parvatam G and G Ravishankar (2009) AgNO3 - A potential regulator of ethylene activity and plant growth modulator. Electron. J. Biotechnol. 12(2): 8-9. doi: 10.2225/vol12-issue2-fulltext-1

Lentini Z, Reyes P, Martinez CP and Roca WM (1995) Androgenesis of highly recalcitrant rice genotypes with maltose and silver nitrate. Plant Sci. 110(1): 127-138. http://www.sciencedirect.com/science/article/pii/0168945295041803

Lightbourn G and Veilleux R (2007) Production and evaluation of somatic hybrids derived from monoploid potato. Am. J Pot. Res. 84: 425-435. http://link.springer. com/ article/10.1007/BF02987188

Osolnik B, Bohanec B and Jelaska S (1993) Stimulation of androgenesis in white cabbage (Brassica oleracea var. capitata) anthers by low temperature and anther dissection. Plant Cell Tiss. Org. Cult. 32(2): 241-246. http://link.springer.com/article/10.1007 /BF00029849

Panahandeh J (2010) Dihaploid induction ability of three clones of Solanum phureja $(2 \mathrm{n}=$ $2 x=24)$ in interploidy cross with $S$. tuberosum $(2 n=4 x=48)$. Acta Agron. Hung. $58(1)$ : 49-54. doi:10.1556/AAgr.58.2010.1.6

Paz MM and Veilleux RE (1999) Influence of culture medium and in vitro conditions of shoot regeneration in Solanum phureja monoploids and fertility of regenerated doubled monoploids. Plant Breed. 118(1): 53-57. http://onlinelibrary.wiley.com/ doi/10.1046/j.1439-0523.1999.118001053.x/abstract

Peloquin S, Werner EJ and GL Yerk (1991) The use of potato haploids in genetics and breeding. In: Chromosome Engineering in Plants: Genetics, Breeding, Evolution, Part B, Gupta PK and Tsuchiya T (Eds.), Elsevier, Amsterdam. p. 79.

Peloquin S, Gabert A and Ortiz R (1996) Nature of 'Pollinator' effect in potato (Solanum tuberosum L.) haploid production. Ann. Bot. 77(5): 539-542. http://aob.oxfordjournals. org/content/77/5/539.short

Pianzzola MJ, Zarantonelli L, González G, Franco Fraguas L and Vázquez A (2005) Genetic, phytochemical and biochemical analyses as tools for biodiversity evaluation of wild Solanum commersonii accessions. Biochem. Syst. Ecol. 33(1): 67-78. http://www. sciencedirect.com/science/article/pii/S0305197804001668

Potato Genome Sequencing Consortium (2011) Genome sequence and analysis of the tuber crop potato. Nature 475(7355): 189-195. doi:10.1038/nature10158.

Powell W (1988) The influence of genotype and temperature pre-treatment on anther culture response in barley (Hordeum vulgare L.). Plant Cell Tiss. Org. Cult. 12(3): 291297. http://link.springer.com/article/10.1007/BF00034371 
Rokka VM (2009) Potato haploids and breeding. In: Advances in Haploid Production in Higher Plants, Touraev A, Forster BP and Jain SM (Eds.), Springer, New York, USA, pp. 199-208.

Sarropoulou V, Dimassi-theriou K and Therios I (2016) Effect of the ethylene inhibitors silver nitrate, silver sulfate, and cobalt chloride on micropropagation and biochemical parameters in the cherry rootstocks CAB-6P and Gisela 6. Turkish J. Biol. doi:10.3906/biy-1505-92

Shariatpanahi ME, Bal U, Heberle-Bors E and Touraev A (2006) Stresses applied for the re-programming of plant microspores towards in vitro embryogenesis. Physiol. Plant. 127(4): 519-534. http://onlinelibrary.wiley.com/doi/10.1111/j.1399-3054.2006.00675. $\mathrm{x} / \mathrm{full}$

Sonnino AS, Tanaka M, Iwanaga and Schilde-Rentscher L (1989) Genetic control of embryo formation in anther culture of diploid potatoes. Plant Cell Rep. 8(2): 105-107. http://link.springer.com/article/10.1007\%2FBF00716850?LI=true\#page-1

Tiainen T (1992) The role of ethylene and reducing agents on anther culture response of tetraploid potato (Solanum tuberosum L.). Plant Cell Rep. 10(12): 604-607. http://link. springer.com/article/10.1007/BF00232379

Staba JE (1969) Plant tissue culture as a technique for the phytochemist. Recent Advances Phytochem. 2: 80-88.

Tai GC and Xiong XY (2005) Haploid production of potatoes by anther culture in doubled haploid production in crop plants: A Manual, Maluszynski M, Kasha KJ, Forster BP and Szarejko I (Eds.), Kluwer Academy Publishers, Dordedrecht, The Netherlands, chapter 2.33 .

Veen H and Overbeek JHM (1989) The action of silver thiosulphate in carnation petals. In: Biochemical and physiological aspects of ethylene production in lower and higher plants, Cligsters HD, Proft M, Marcelle R and Van Poucke M (Eds.), Kluwer Academic Publishers, Dordedrecht, The Netherlands, pp. 109-117.

Veilleux RE, Booze-Daniels J and Pehu E (1995) Anther culture of a 2n pollen producing clone of Solanum phureja Juz. \& Buk. Can. J. Genet. Cytol. 27(5): 559-564. http:// www.nrcresearchpress.com/doi/abs/10.1139/g85-082\#.VzZkRIThCM8

Visser RGF, Bachem CWB, Boer JM, Bryan GJ, Chakrabati SK, Feingold S, Gromadka R, van Ham RCHJ, Huang S, Jacobs JME, Kuznetsov B, Melo PE, Milbourne D, Orjeda G, Sagredo B and Tang X (2009) Sequencing the potato genome: outline and first results to come from the elucidation of the sequence of the world's third most important food crop. Am. J. Potato Res. 86(6): 417-429. doi:10.1007/s12230-009-9097-8

Wang Q, Ran Y, Yu B, Chen X and Wang D (2014) Embryogenesis and haploid induction using anther culture in lovage (Levisticum officinale W.D.J. Koch). In Vitro Cell. Dev. Biol.-Plant 50: 525-533. doi: 10.1007/s11627-014-9610-8

Wenzel G, Hoffmann F and Thomas E (1977) Increased induction and chromosome doubling of androgenetic haploid rye. Theor Appl Genet 51(2): 81-86. http://link. springer.com/article/10.1007/BF00299481

Wilkinson MJ, Bennett ST, Clulow SA, Allainguillaume J, Harding K and Bennett, MD (1995) Evidence for somatic translocation during potato dihaploid induction. Heredity 74: 146-151. 
Zhong XB, de Jong JH, Zabel P (1996) Preparation of tomato meiotic pachytene and mitotic metaphase chromosomes suitable for fluorescence in situ hybridisation (FISH). Chromosome Res. 4(1): 24-28. http://link.springer.com/article/10.1007/ BF02254940

Zuluaga A, Solé M, Lu H, Góngora-Castillo E, Vaillancourt B, Coll N, Buell C and Valls M (2015) Transcriptome responses to Ralstonia solanacearum infection in the roots of the wild potato Solanum commersonii. BMC Genomics 16: 246. http:// bmcgenomics.biomedcentral.com/articles/10.1186/s12864-015-1460-1 